\title{
Sizing up the ecological role of sharks as predators
}

\author{
Michelle R. Heupel ${ }^{1,2, *}$, Danielle M. Knip ${ }^{3}$, Colin A. Simpfendorfer ${ }^{2}$, \\ Nicholas K. Dulvy ${ }^{4}$
}

\author{
${ }^{1}$ Australian Institute of Marine Science, PMB No 3, Townsville, Queensland 4810, Australia \\ ${ }^{2}$ Centre for Sustainable Tropical Fisheries and Aquaculture \& School of Earth and Environmental Sciences, \\ James Cook University, Townsville, Queensland 4811, Australia \\ ${ }^{3}$ Sea Around Us Project, Fisheries Centre, 2202 Main Mall, The University of British Columbia, Vancouver, \\ British Columbia V6T 1Z4, Canada \\ ${ }^{4}$ Earth to Ocean Research Group, Department of Biological Sciences, Simon Fraser University, Burnaby, \\ British Columbia V5A 1S6, Canada
}

\begin{abstract}
The decline of predators in a variety of ecosystems has transformed community structure through mesopredator release and trophic cascades. Elasmobranch fishes, one of the earth's most ubiquitous and diverse clade of predatory species, provide a model group for defining marine predator roles. We consider whether the ecological predatory role of sharks is adequately defined by terrestrial-derived notions of apex- and mesopredation. Indeterminate growth and ontogenetic diet shifts may mean species-level classification of predatory roles is inadequate. We propose that examining the trophic level and body size of species might be the most pragmatic and informative way to define the ecological roles of predators.
\end{abstract}

KEY WORDS: Top-down control · Predator-prey interactions · Predation risk · Home range • Ecology of fear

\section{DEFINITION OF PREDATORS}

Top predators and large-bodied megafauna are often the most affected elements of exploited ecosystems, both on land and in the sea; and the top-down control these predators exert on prey species can significantly alter community structure (Pinnegar et al. 2000, Laliberte \& Ripple 2004). The loss of predation and the resultant indirect effects of mesopredator release and trophic cascades have resulted in widespread trophic downgrading of ecosystems (Crooks \& Soulé 1999, Baum \& Worm 2009, Estes et al. 2011). For example, both the loss of wolves from Yellowstone National Park in the USA and declines in largebodied shark populations of the western North Atlantic Ocean have been reported to cause mesopredator release and trophic cascades (Berger \& Conner 2008, Baum \& Worm 2009, Ferretti et al. 2010). Recently, much of the research focus has been on the response of prey to predators; here, we focus our attention on the ecological role of the predator. Despite some compelling and widely-cited case studies, our understanding of the dynamics of predators in regulating prey populations is still limited, yet predation is recognised as a key ecological and evolutionary process (Estes et al. 2011). Particularly in the marine realm, gaining sufficient knowledge of large, highly mobile predators to define their roles is challenging. The widespread nature of these species makes them difficult to target, handle and experimentally manipulate for the purposes of research. Thus, defining the impacts of large marine predators is problematic.

Our understanding of the ecological role of predators is often constrained by the limited range of ways to classify the trophic role of species and individuals. Predators are most commonly defined by their spe- 
cies identity in both terrestrial (e.g. wolf, mountain lion, coyote) and aquatic (e.g. white shark, orca, saltwater crocodile) ecosystems. However, a complete understanding of ecosystem function requires definition of the role predatory species play in these systems and their interactions with other species. For example, is a species functioning as an apex predator or as a mesopredator? Is predation concentrated or diffuse? Concentrated predation within a community occurs when one predator species determines patterns of community structure, such as the behaviour, distribution, composition and diversity of prey (Menge et al. 1994). In contrast, diffuse predation involves a suite of species all preying upon prey populations but with high redundancy, such that individual predator species have little measurable effect (Menge et al. 1994). Defining the role of predators is a useful step toward understanding the consequences of their removal or depletion within a system. In the marine literature, the ecological importance of sharks has been reviewed (e.g. Heithaus et al. 2010), but there is a lack of discrete definitions of marine predators. Thus, we consider terrestrial definitions of apex and mesopredation and their potential to clarify predatory roles in marine ecosystems.

Terrestrial ecologists have provided working definitions for both apex predation and mesopredators that may be broadly applicable to marine systems. Apex predators have been defined as species that occupy the top trophic position in a community and are noted to: (1) often have strong effects on trophic dynamics and diversity of systems, (2) affect mesopredators via lethal encounters or influencing behaviour, and (3) kill smaller predators for food and to avoid competition (Ritchie \& Johnson 2009). For example, in eastern Maine and California, USA, coyotes strongly influence community dynamics as an apex predator, such as limiting the habitat use of red foxes (Harrison et al. 1989) and suppressing and killing mesopredators like bobcats, gray foxes and opossums (Crooks \& Soulé 1999, Fedriani et al. 2000). Apex predator species are also often described as large-bodied, specialised hunters that tend to have large home ranges where they may only visit specific locations within them periodically (Prugh et al. 2009). Based on this framework, apex predators such as coyotes and wolves would produce concentrated predation risk in a community.

In contrast to apex predators, mesopredators comprise any mid-ranking predator in a food web regardless of size or taxonomy (Prugh et al. 2009, Ritchie \& Johnson 2009). Mesopredators are more likely to provide diffuse predation within a community based on their relative height in the trophic pyramid. Due to greater energy availability and species richness at lower trophic levels (Lindeman 1942, May 1988), the expectation is that mesopredators should exploit a wider portfolio of shared food resources, and as such would be less specialised, with less influence on the behaviour of other species (Prugh et al. 2009). However, unlike apex predators, the definition of mesopredators can be highly context-specific: the same species may function as a mesopredator in one habitat and an apex predator in another. For example, coyotes function as mesopredators in the Greater Yellowstone Ecosystem where wolves have been reintroduced (Berger \& Conner 2008), while they have ascended to the role of apex predator in other areas of North America where wolves and other large predators have been extirpated (Crooks \& Soulé 1999). Thus, the interaction of a predator with other species within an ecosystem is critical to a clear definition of their role.

\section{THE CHALLENGE OF CLASSIFYING PREDATION ROLES IN THE SEA}

Elasmobranch fishes, particularly sharks, comprise one of the most widespread and diverse clades of predators (Compagno 1990, Cortés 1999, White \& Last 2012), providing a model for refining predatory roles. Many shark species have been labelled as apex predators, such as bull sharks $\left(\mathrm{O}^{\prime}\right.$ Connell et al. 2007), copper sharks (Benavides et al. 2011) and Caribbean reef sharks (Maljkovic \& Cote 2011), and indeed whole shark assemblages are often labelled generically as 'apex', 'top predators' or 'great sharks' (e.g. Ceccarelli \& Ayling 2010). However, it is usually unclear whether such labelling of predator species (or even whole predator assemblages) as apex predators conforms to definitions proposed within the terrestrial literature. To the best of our knowledge, no similar comparable definition has been fully described or evaluated for marine ecosystems.

While a behavioural definition has been considered for marine predators, we suggest a traits-based definition could be pragmatically applied to a broader range of study systems. This is not to downplay the behavioural influence of large predators, but simply because of the difficulty of undertaking sufficient species-by-species field observations to evaluate the degree of fear imposed by species. As stated above, the logistics of observing wide-ranging, large-bodied predatory sharks are difficult. One of the few examples of the pertinence of the behavioural role of sharks highlights similarities in predation pressure by 
tiger sharks and wolves - suggesting application of the behavioural definition can be appropriate (Wirsing \& Ripple 2011). The authors showed that tiger sharks and wolves elicited similar prey responses including: encounter avoidance, escape facilitation, and increased vigilance. Specifically, the seasonal presence of tiger sharks in Shark Bay, Australia, was found to limit the habitat use and abundance of dolphins and dugongs in productive, shallow areas (Heithaus \& Dill 2002, 2006, Wirsing et al. 2007, Wirsing \& Heithaus 2007). Wirsing \& Ripple (2011) concluded that similarities exist between predators in marine and terrestrial systems, and recommended greater exchange of concepts between researchers in these communities. One additional example is the presence of sleeper sharks in Alaska, which has been shown to alter the diving behaviour of seals (Frid et al. 2007). Beyond these 2 examples, information that could be used to further evaluate the applicability of this behavioural definition of shark apex predation in marine systems is sparse and hard to obtain. In general, marine ecologists rarely have information on the response to predator presence or community-level impacts.

Apex predator species are generally those that have the highest trophic level in their community, and hence have no predators themselves. Trophic level can be generically defined by the proportional contribution of different trophic level diet items, such as collated by Cortés (1999). For example, stable isotope analyses of the tissue samples of individuals and species can provide location-specific estimates of trophic level (Post 2002, Matich et al. 2011), and could be used to identify mesopredatory and apex size classes of elasmobranchs. However, it is worth recognizing that stable isotope and diet analyses do not account for non-consumptive effects (i.e. fear and dominance) exerted by some predators (Heithaus et al. 2008). These approaches also do not indicate when items have been consumed as part of a predatory event or from scavenging (e.g. feeding on whale carcasses). Therefore, the diet and trophic role of the species should be considered within the greater context of size and behavioural effects.

\section{APEX SIZE CLASSES}

While size can be important in terrestrial ecosystems, size is crucial in marine ecosystems - which tend to be dominated by indeterminate organisms that grow continuously throughout their lives (Trebilco et al. 2013). Individual function changes due to ontogenetic diet shifts as organisms grow in size (Karpouzi
\& Stergiou 2003, Pinnegar et al. 2003). The consequence is that size-structuring within communities, rather than species identity, is an important factor in determining the strength of competitive and predatory interactions (Dickie et al. 1987, Kerr \& Dickie 2001). For example, studies have shown high overlap in diet between similar-sized sharks regardless of maturity state and species identity (e.g. Bethea et al. 2004). Therefore, designation of marine species into apex and mesopredator categories should consider the life stage and size of individuals. This can also be important on land; for example, the predatory role of young wolves or even solitary adult individuals is lower than the per capita impact of larger, experienced individuals hunting in a pack. Younger, solitary individuals are vulnerable to direct predation and the indirect effects of predation risk imposed by apex and mesopredators, and would therefore induce little top-down pressure. Similarly, small juvenile stages of even the largest shark species would not qualify as apex predators for 2 reasons: their narrower gape size restricts them to feeding on smaller prey, and their vulnerability to predation from larger sharks and documented avoidance of large predators (Heupel \& Hueter 2002). Gape size may also be a limiting factor for some species that grow to a large size but are limited in what they can feed on due to relatively small gape size (e.g. thresher shark). In general, the juvenile life stages of many coastal sharks tend to be found in shallow waters - possibly to minimise predation risk (Branstetter 1990, Heupel \& Simpfendorfer 2005, Wetherbee et al. 2007). Thus, the higher risk of predation upon small species and size classes of sharks would probably have an impact on their non-consumptive role through ecology of fear effects (e.g. increased vigilance, escape behaviour, etc.). In contrast, populations with a full age structure consisting of numerous largebodied adults, such as tiger and white sharks, can affect the presence of other species via predation, and suppress species though fear and dominance (e.g. Heithaus \& Dill 2002, 2006, Wirsing et al. 2007, Wirsing \& Heithaus 2007). As such, larger-bodied adult sharks might also fit the behavioural criteria of an apex predator in addition to the individual-level traits-based definition.

Many species' traits change with body size, such that larger-bodied animals use larger home ranges (Jetz et al. 2004), eat larger prey (Pinnegar et al. 2003) and typically have increased dietary specialisation (Scharf et al. 2000). Energy use and home range are tightly linked, and within a trophic level the energy available per unit area is the same irrespective of the size of an animal due to the energetic 
equivalence rule (Damuth 1981). For multiple trophic levels, the energy available per unit area is further decreased as a result of the reduction in energy availability to higher trophic levels due to the inefficiency of energy transfer from resource to consumer-typically less than $10 \%$ of prey production is converted into predator production (Lindeman 1942). Therefore, larger animals with high energetic requirements can acquire sufficient prey only by having large ranges (Brown \& Maurer 1989). Due to the reduced energy per unit area as mean trophic level increases, larger sharks feeding at higher trophic levels would presumably require more area in which to forage than if they remained at their original trophic level. For example, the frequency of occurrence of large prey items in the stomachs of tiger sharks increased as shark body size increased in Hawaii, Australia and New Caledonia (Lowe et al. 1996). Ontogenetic diet shifts were hypothesized based on increased body size and expanded range and exploitation of habitats of larger sharks. Hence, we might talk of apex size classes rather than apex species in relation to sharks and other marine predators that grow indeterminately throughout their lives.

Using the criterion of apex size classes, the categorisation of sharks as apex predators would be restricted mainly to adults of large-bodied and wide-ranging species that influence many species within a community. Use of this definition would limit the term apex predator to large individuals $(>3 \mathrm{~m})$ such as older juvenile or adult white, tiger, hammerhead and dusky sharks. However, ontogenetic changes in specieslevel traits (e.g. home range) are independent of trophic level-so simply having a larger body size, larger range, and consuming larger prey may not always mean that the species is an apex predator throughout its range or throughout all size classes. While apex predators would exhibit these traits, many other species could also have these characteristics but not be apex predators. Therefore, measuring the type and level of interactions with other species is crucial when defining the predatory role of sharks in communities. A key caveat in defining apex size classes is that body size can only be used within the constraints that the largest sharks (e.g. basking and whale sharks) feed on prey of especially small size classes at low trophic levels, a consequence of the absolute low energy available to the largest predators as a result of the inefficiency of energy transfer (Jennings et al. 2008). Another exception would include large predators that consume large, lower trophic level prey (e.g. tiger sharks consuming herbivores such as dugong and sea turtles; Simpfendorfer et al. 2001).

\section{DIFFUSE PREDATION}

Darwin coined the term 'diffuse competition' to convey the effect of numerous tropical species on limiting the geographic range of mid-latitude species. The term can be readily understood as the competition shadow resulting from the sum of the LotkaVolterra competition coefficients (Scheffer \& van Nes 2006, Vergnon et al. 2012). In the marine environment, where there are numerous predators and predatory size classes that tend to feed in a sizebased rather than a species-based manner (Duplisea 2005), diffuse predation is likely to be widespread. Diffuse predation according to a prey size window and a predator to prey size distribution are ubiquitous features of size spectra models of energy flow in aquatic ecosystems (Blanchard et al. 2011). Using the trophic level definition of apex and mesopredators and current knowledge of shark diets, most species and small juvenile stages of the largest species would be categorised as mesopredators. For many estuarine and marine communities, this would suggest that sharks provide a diffuse predator community composed of individuals feeding on similar prey items in a size-based manner (Kinney et al. 2011, Vaudo \& Heithaus 2011). Communal nursery areas provide a good example of a community of mesopredators. These areas are found in coastal bays and estuaries mainly in tropical and subtropical regions, and are known to support multiple species of juvenile and small-bodied sharks that all typically feed on small teleosts (Castro 1993, Simpfendorfer \& Milward 1993). In these communities, a large number of small sharks (and large-bodied teleosts) are exerting diffuse, sizebased predation pressure and fear on teleost species. Such inshore habitats might be expected to have a high degree of resilience due to high redundancy in the species and size classes providing predatory control. Loss of one or more of these species would likely have little impact on the overall dynamics of the region due to the ability of other small-bodied individuals or species to continue to fill this role. In scenarios where shark species are solitary residents, such as a single species nursery, small individuals may share a similar predatory role as large piscivorous teleosts. As these small sharks would still be exposed to potential predators, their role would remain as a mesopredator within an ecosystem that also supports teleost mesopredators.

In contrast, a large-bodied coastal shark with a broad home range would provide a different level of predation based on its transient presence within the communal nursery habitat. The dynamics of coastal 
nursery areas exemplify the presence of concentrated (hammerhead) and diffuse (small-bodied shark) predation risk in these systems. This hypothesis is consistent with Ecopath model findings by Kitchell et al. (2002), who reported that simulated shark removal within an open-ocean ecosystem resulted in limited perturbation. Further Ecopath modelling by Carlson (2007) revealed how the reduction of one shark species increased abundance of others. Carlson hypothesised that this was the result of other shark species adjusting to fill the vacated niche. The likely existence of size-varying predatory roles combined with diffuse predation and guild diversity suggests that most sharks, as individuals or as species, do not act as apex predators and have potentially limited influence on ecosystem biodiversity.

\section{CORAL REEFS AS A COMMUNITY CASE STUDY}

Recent research has indicated that reef shark populations have been dramatically altered by fishing pressure and other human impacts (e.g. Friedlander \& DeMartini 2002, Robbins et al. 2006, Sandin et al.
2008, Heupel et al. 2009, Ward-Paige et al. 2010). These studies have typically used either underwater visual survey techniques or fishing data to examine the presence and abundance of shark species at different coral reef platforms. Much of this research has focused on contrasts between human-inhabited and isolated reefs or regions that have been open or closed to fishing, and has found that in general, sharks occur more often at isolated reef sites that are closed to fishing (Friedlander \& DeMartini 2002, Garla et al. 2006, Robbins et al. 2006, Sandin et al. 2008, Nadon et al. 2012). Separate from this issue are the implications of predator roles in these communities. Based on the proposed definitions of apex and mesopredators, the vast majority of reef-attached species would be categorised as mesopredators; with apex predators in these regions limited to large species such as tiger, bull, silvertip and hammerhead sharks (Fig. 1). From this perspective, coral reef communities, and especially the most diverse ones, would function similarly to that of communal nursery areas described above, with multiple mesopredator species present to feed on teleost populations, providing diffuse predation.

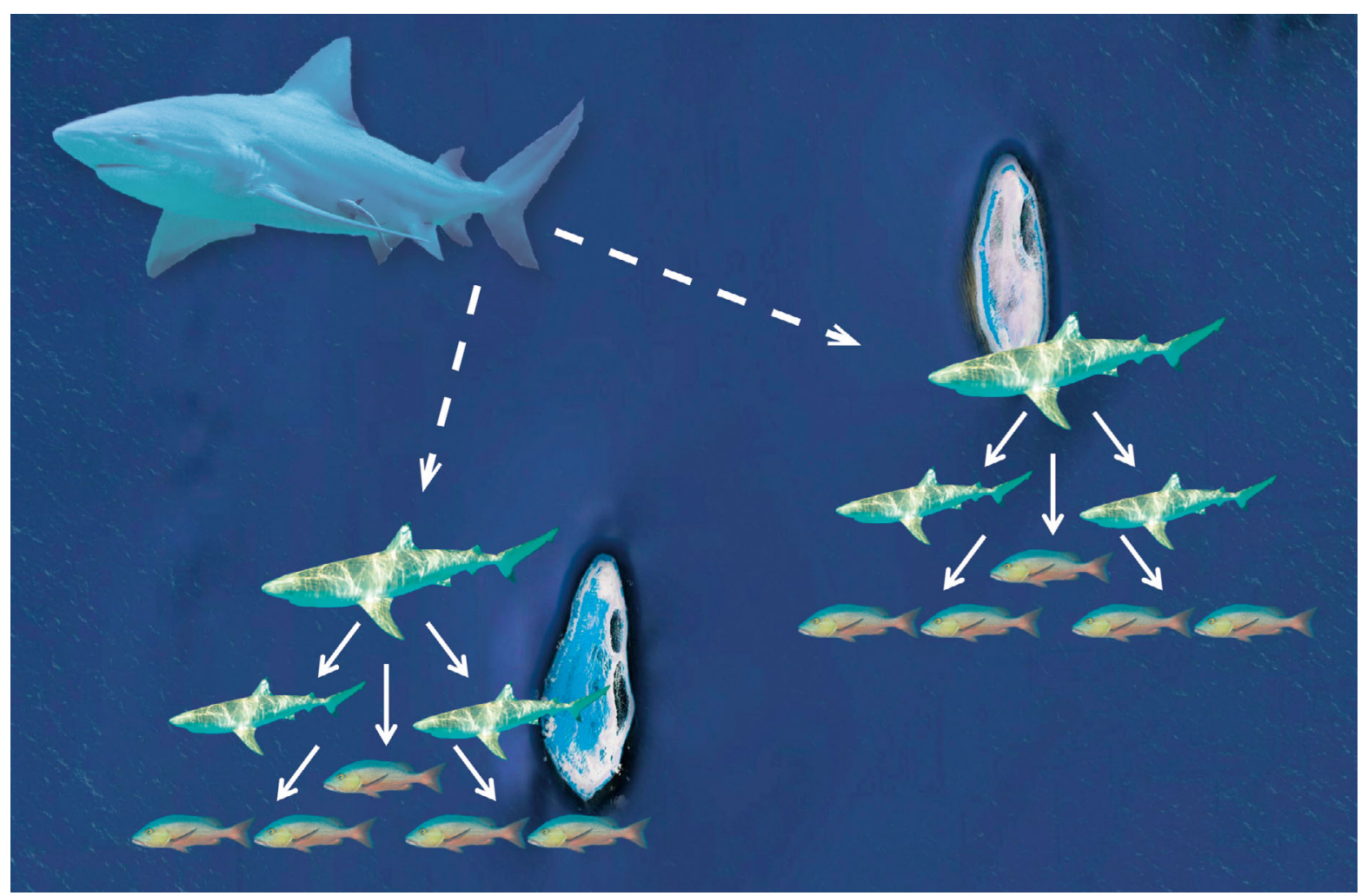

Fig. 1. Diagram indicating permanent (mesopredator) and transient (apex predator) predation pressure on reef systems where the single apex predator exerts concentrated predation while multiple smaller mesopredators exert diffuse predation. Solid arrows indicate permanent food web connections at the local reef scale; dashed arrows indicate transient connections and predation events of wider-ranging apex species and size classes 

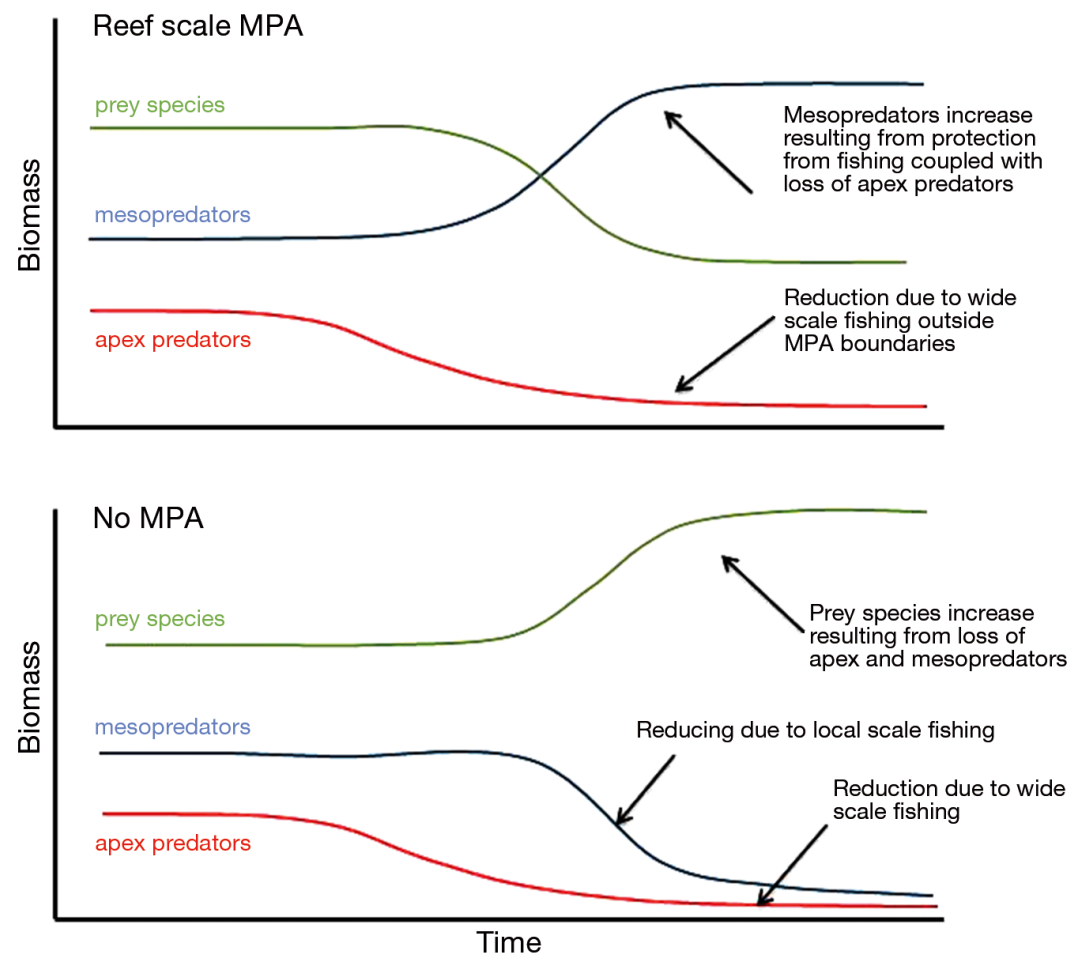

Fig. 2. Conceptual diagram outlining the loss of apex predators from reef regions and corresponding system responses where a marine protected area (MPA) is present (upper) or absent (lower). Presence of MPAs leads to different states of equilibrium on individual reefs

Our size-based view of the classification of predatory roles raises important questions about what objectives to manage, and how these objectives can be best achieved. Protection of reef communities through marine protected areas (MPAs) or fisheries regulation (or indeed, naturally on those few locations far from human population centres) would ensure the mesopredator sharks on these reefs are sheltered from fishing pressure. However, the same may not be true for apex predators because their broad movement patterns and large home ranges (Meyer et al. 2009) would expose them to a greater diversity of fishing fleets and gears, and thus a greater overall mortality than the smaller-ranging, reef-dwelling mesopredators. Hence, the apex predators of coral reefs may be silently eliminated by offshore pelagic longline fisheries, unbeknownst to those managing reef diversity and function (Cox et al. 2002). Therefore, reef-based MPAs are not adequate to protect these species. As such, managers run the risk of encountering pitfalls when examining the success of MPAs by substituting space-for-time measures of success. If apex predators spend limited time in MPAs then the spatial closures are not successful. Securing the ecological role of apex preda- tors on coral reefs and other coastal ecosystems may require that such system-crossing species and size classes be prioritised for assessment and protection from adverse effects of pelagic fleets. We also caution that the cryptic loss of reef-hopping, ocean-crossing apex sharks may have resulted in mesopredator release, inflating the abundance of intermediate mesopredatory sharks at remote atolls (Fig. 2, and e.g. Sandin et al. 2008). Avoiding and mitigating these impacts may require consideration of the ecosystem- and jurisdiction-crossing movements of apex species and size classes. Therefore, management needs to consider not only the effect of reef-based spatial closure, but the amount of time these regions provide shelter to large, mobile, apex species. Future research needs to explicitly consider the ecological roles and impacts of different size classes and species of sharks. An improved understanding of how sharks interact with other species is critical to a more complete understanding of their role within ecosystems.

\section{CONCLUSIONS}

Defining the predatory roles of individuals and species in marine communities is a potentially complex undertaking due to our frequent inability to observe behavioural responses of prey or the community response. However, consistent definitions and use of terminology within and across marine and terrestrial communities will clarify the role of species. Terrestrial definitions of the apex predator include intrinsic features based on what a species is (i.e. individual traits-based definition) and extrinsic features based on what a species does (i.e. behavioural definition and wider community-level impact definition). We propose that using these definitions and categorising indeterminate growing species, such as sharks, into apex size classes may be the most pragmatic and informative way to define predators in marine communities. Following these criteria, most shark species and size classes are in fact best described in the role of mesopredator. The ecological role of sharks within the diverse and impacted marine environment requires careful consideration. 
Acknowledgements. M.R.H. is the recipient of an Australian Research Council Future Fellowship (project \#FT100101004), N.K.D. is funded by the Natural Science and Engineering Research Council of Canada and Canada Research Chairs program.

\section{LITERATURE CITED}

Baum JK, Worm B (2009) Cascading top-down effects of changing oceanic predator abundances. J Anim Ecol 78: 699-714

Benavides MT, Feldheim KA, Duffy CA, Wintner S and others (2011) Phylogeography of the copper shark (Carcharhinus brachyurus) in the southern hemisphere: implications for the conservation of a coastal apex predator. Mar Freshw Res 62:861-869

> Berger KM, Conner MM (2008) Recolonising wolves and mesopredator suppression of coyotes: impacts on pronghorn population dynamics. Ecol Appl 18:599-612

Bethea DM, Buckel JA, Carlson JK (2004) Foraging ecology of the early life stages of four sympatric shark species. Mar Ecol Prog Ser 268:245-264

Blanchard J, Law R, Castle M, Jennings S (2011) Coupled energy pathways and the resilience of size-structured food webs. Theor Ecol 4:289-300

Branstetter S (1990) Early life-history implications of selected carcharhinoid and lamnoid sharks of the northwest Atlantic. In: Pratt HL, Gruber SH, Taniuchi T (eds) Elasmobranchs as living resources: advances in the biology, ecology, systematics, and the status of the fisheries. Proceedings of the 2nd United States-Japan workshop. NOAA Technical Report NMFS 90, p 17-28

Brown JH, Maurer BA (1989) Macroecology: the division of food and space among species on continents. Science 243:1145-1150

Carlson JK (2007) Modeling the role of sharks in the trophic dynamics of Apalachicola Bay, Florida. Am Fish Soc Symp 50:281-300

> Castro JI (1993) The shark nursery of Bulls Bay, South Carolina, with a review of the shark nurseries of the southeastern coast of the United States. Environ Biol Fishes 38: $37-48$

Ceccarelli D, Ayling T (2010) Role, importance and vulnerability of top predators on the Great Barrier Reef-a review. Research Publication No. 105, Great Barrier Reef Marine Park Authority, Townsville

> Compagno LJV (1990) Alternative life-history styles of cartilaginous fishes in time and space. Environ Biol Fishes 28: 33-75

> Cortés E (1999) Standardized diet compositions and trophic levels of sharks. ICES J Mar Sci 56:707-717

> Cox SP, Essington TE, Kitchell JF, Martell SJD, Walters CJ, Boggs C, Kaplan I (2002) Reconstructing ecosystem dynamics in the central Pacific Ocean, 1952-1998. II. A preliminary assessment of the trophic impacts of fishing and effects on tuna dynamics. Can J Fish Aquat Sci 59: 1736-1747

Crooks KR, Soulé ME (1999) Mesopredator release and avifaunal extinctions in a fragmented system. Nature 400: 563-566

Damuth J (1981) Population density and body size in mammals. Nature 400:564-566

> Dickie LM, Kerr SR, Boudreau PR (1987) Size-dependent processes underlying regularities in ecosystem structure.
Ecol Monogr 57:233-250

Duplisea DE (2005) Running the gauntlet: the predation environment of small fish in the northern Gulf of St Lawrence, Canada. ICES J Mar Sci 62:412-416

> Estes JA, Terborgh J, Brashares JS, Power ME and others (2011) Trophic downgrading of planet earth. Science 333:301-306

> Fedriani JM, Fuller TK, Sauvajot RM, York EC (2000) Competition and intraguild predation among three sympatric carnivores. Oecologia 125:258-270

Ferretti F, Worm B, Britten GL, Heithaus MR, Lotze HK (2010) Patterns and ecosystem consequences of shark declines in the ocean. Ecol Lett 13:1055-1071

Frid A, Dill LM, Thorne RE, Blundell GM (2007) Inferring prey perception of relative danger in large-scale marine systems. Evol Ecol Res 9:635-649

> Friedlander AM, DeMartini EE (2002) Contrasts in density, size, and biomass of reef fishes between the northwestern and the main Hawaiian islands: the effects of fishing down apex predators. Mar Ecol Prog Ser 230: 253-265

> Garla RC, Chapman DD, Shivji MS, Wetherbee BM, Amorim AF (2006) Habitat of juvenile Caribbean reef sharks, Carcharhinus perezi, at two oceanic insular marine protected areas in the southwestern Atlantic Ocean: Fernando de Noronha Archipelago and Atol das Rocas, Brazil. Fish Res 81:236-241

- Harrison DJ, Bissonette JA, Sherburne JA (1989) Spatial relationships between coyotes and red foxes in eastern Maine. J Wildl Manag 53:181-185

Heithaus MR, Dill LM (2002) Food availability and tiger shark predation risk influence bottlenose dolphin habitat use. Ecology 83:480-491

Heithaus MR, Dill LM (2006) Does tiger shark predation risk influence foraging habitat use by bottlenose dolphins at multiple spatial scales? Oikos 114:257-264

Heithaus MR, Frid A, Wirsing AJ, Worm B (2008) Predicting ecological consequences of marine top predator declines. Trends Ecol Evol 23:202-210

Heithaus MR, Frid A, Vaudo JJ, Worm B, Wirsing AJ (2010) Unraveling the ecological importance of elasmobranchs. In: Carrier JC, Musick JA, Heithaus MR (eds) Sharks and their relatives II: Biodiversity, adaptive physiology, and conservation. CRC Press, Boca Raton, FL, p 607-633

> Heupel MR, Hueter RE (2002) Importance of prey density in relation to the movement patterns of juvenile blacktip sharks (Carcharhinus limbatus) within a coastal nursery area. Mar Freshw Res 53:543-550

Heupel MR, Simpfendorfer CA (2005) Quantitative analysis of aggregation behavior in juvenile blacktip sharks. Mar Biol 147:1239-1249

> Heupel MR, Williams AJ, Welch DJ, Ballagh A and others (2009) Effects of fishing on tropical reef associated shark populations on the Great Barrier Reef. Fish Res 95: 350-361

> Jennings S, Melin F, Blanchard JL, Forester RM, Dulvy NK, Wilson RW (2008) Global-scale predictions of community and ecosystem properties from simple ecological theory. Proc R Soc B 275:1375-1383

Jetz W, Carbone C, Fulford J, Brown JH (2004) The scaling of animal space use. Science 306:266-268

Karpouzi VS, Stergiou KI (2003) The relationships between mouth size and shape and body length for 18 species of marine fishes and their trophic implications. J Fish Biol 62:1353-1365 
Kerr SR, Dickie LM (2001) The biomass spectrum: a predator-prey theory of aquatic production. Columbia University Press, New York, NY

Kinney MJ, Hussey NE, Fisk AT, Tobin AJ, Simpfendorfer CA (2011) Communal or competitive? Stable isotope analysis provides evidence of resource partitioning within a communal shark nursery. Mar Ecol Prog Ser 439: 263-276

Kitchell JF, Essington TE, Boggs CH, Schindler DE, Walters CJ (2002) The role of sharks and longline fisheries in a pelagic ecosystem of the Central Pacific. Ecosystems 5: 202-216

Laliberte AS, Ripple WJ (2004) Range contractions of North American carnivores and ungulates. Bioscience 54:123-138

> Lindeman RL (1942) The trophic-dynamic aspect of ecology. Ecology 23:399-417

Lowe CG, Wetherbee BM, Crow GL, Tester AL (1996) Ontogenetic dietary shifts and feeding behavior of the tiger shark, Galeocerdo cuvier, in Hawaiian waters. Environ Biol Fishes 47:203-211

Maljkovic A, Cote IM (2011) Effects of tourism-related provisioning on the trophic signatures and movement patterns of an apex predator, the Caribbean reef shark. Biol Conserv 144:859-865

Matich P, Heithaus MR, Layman CA (2011) Contrasting patterns of individual specialization and trophic coupling in two marine apex predators. J Anim Ecol 80:294-305

> May RM (1988) How many species are there on the earth? Science 241:1441-1449

> Menge BA, Berlow EL, Blanchette CA, Navarrete SA, Yamada SB (1994) The keystone species concept: variation in interaction strength in a rocky intertidal habitat. Ecol Monogr 64:249-286

Meyer CG, Clark TB, Papastamatiou YP, Whitney NM, Holland KN (2009) Long-term movement patterns of tiger sharks Galeocerdo cuvier in Hawaii. Mar Ecol Prog Ser 381:223-235

> Nadon MO, Baum JK, Williams ID, McPherson JM and others (2012) Re-creating missing population baselines for Pacific reef sharks. Conserv Biol 26:493-503

O'Connell MT, Shepherd TD, O'Connell AMU, Myers RA (2007) Long-term declines in two apex predators, bull sharks (Carcharhinus leucas) and alligator gar (Atractosteus spatula), in Lake Pontchartrain, an oligohaline estuary in southeastern Louisiana. Estuaries Coasts 30: 567-574

Pinnegar JK, Polunin NVC, Francour P, Badalamenti F and others (2000) Trophic cascades in benthic marine ecosystems: lessons for fisheries and protected-area management. Environ Conserv 27:179-200

Pinnegar JK, Trenkel VM, Tidd AN, Dawson WA, Du Buit MH (2003) Does diet in Celtic Sea fishes reflect prey availability? J Fish Biol 63:197-212

Post DM (2002) Using stable isotopes to estimate trophic position: models, methods, and assumptions. Ecology 83: 703-718

Prugh LR, Stoner CJ, Epps CW, Bean WT, Ripple WJ, La-

Editorial responsibility: Christine Paetzold,

Oldendorf/Luhe, Germany liberte AS, Brashares JS (2009) The rise of the mesopredator. Bioscience 59:779-791

- Ritchie EG, Johnson CN (2009) Predator interactions, mesopredator release and biodiversity conservation. Ecol Lett 12:982-998

Robbins WD, Hisano M, Connolly SR, Choat JH (2006) Ongoing collapse of coral-reef shark populations. Curr Biol 16:2314-2319

Sandin SA, Smith JE, DeMartini EE, Dinsdale EA and others (2008) Baselines and degradation of coral reefs in the Northern Line Islands. PLoS ONE 3:e1548

> Scharf FS, Juanes F, Rountree RA (2000) Predator size-prey size relationships of marine fish predators: interspecific variation and effects of ontogeny and body size on trophic-niche breadth. Mar Ecol Prog Ser 208:229-248

Scheffer M, van Nes EH (2006) Self-organized similarity, the evolutionary emergence of groups of similar species. Proc Natl Acad Sci USA 103:6230-6235

Simpfendorfer CA, Milward NE (1993) Utilization of a tropical bay as a nursery area by sharks of the Families Carcharhinidae and Sphyrnidae. Environ Biol Fishes 37: 337-345

> Simpfendorfer CA, Goodreid AB, McAuley RB (2001) Size, sex and geographic variation in the diet of the tiger shark, Galeocerdo cuvier, from Western Australian waters. Environ Biol Fishes 61:37-46

> Trebilco R, Baum JK, Salomon AK, Dulvy N (2013) Ecosystem ecology: size-based constraints on the pyramids of life. Trends Ecol Evol 28:423-431

> Vaudo JJ, Heithaus MR (2011) Dietary niche overlap in a nearshore elasmobranch mesopredator community. Mar Ecol Prog Ser 425:247-260

> Vergnon R, van Nes EH, Scheffer M (2012) Emergent neutrality leads to multimodal species abundance distributions. Nat Commun 3:663

- Ward-Paige CA, Mora C, Lotze HK, Pattengill-Semmens C, McClenachan L, Arias-Castro E, Myers RA (2010) Largescale absence of sharks on reefs in the greaterCaribbean: a footprint of human presence. PLoS ONE 5: e11968

- Wetherbee BM, Gruber SH, Rosa RS (2007) Movement patterns of juvenile lemon sharks Negaprion brevirostris within Atol das Rocas, Brazil: a nursery characterized by tidal extremes. Mar Ecol Prog Ser 343:283-293

White WT, Last PR (2012) A review of the taxonomy of chondrichthyan fishes: a modern perspective. J Fish Biol 80: 901-917

- Wirsing AJ, Heithaus MR (2007) Living on the edge: dugongs prefer to forage in microhabitats allowing for escape from rather than avoidance of predators. Anim Behav 74:93-101

Wirsing AJ, Ripple WJ (2011) A comparison of shark and wolf research reveals similar behavioral responses by prey. Front Ecol Environ 9:335-341

> Wirsing AJ, Heithaus MR, Dill LM (2007) Fear factor: do dugongs (Dugong dugon) trade food for safety from tiger sharks (Galeocerdo cuvier)? Oecologia 153:1031-1040

Submitted: April 2, 2013; Accepted: October 10, 2013

Proofs received from author(s): December 19, 2013 